\title{
The Role of Talent and Skill in Visual Communication Design Education/Practice: Three Case Studies from Jordan
}

\author{
Hussam A. Darwish Al Qur'an
}

\author{
Graphic Design Department, Faculty of Art \& Design, Zarqa University, Jordan
}

\begin{abstract}
This paper aims to explore more issues informing contemporary graphic design education to produce qualified graphic designers ready for the job market. The paper examines the role of talent and skill, with the purpose to answer the question of which one is more critical when producing visual communication materials. To answer this question, the researcher conducted and supervised several experiments on design students and fresh graduates over a period of two years. The students were exposed to different assignments in which some of these assignments were to produce designs for actual clients, budget, and deadlines. The assignments included designing and producing a multipage publication, short movie, and poster design. All participants in this study were unfamiliar with the proper techniques and programs, besides the equipment needed to produce their assignments. They were asked to attend briefings and follow-up meetings with the clients. They have been treated as full-time employees; they worked eight hours a day and were given tight deadlines to deliver. The study found that both talent and skill are essential concerning practicing visual communication design. It also revealed that talent ranks before skill.
\end{abstract}

Keywords: talent; skill; visual communication design; design education

\section{Introduction}

Most of the Jordanian graphic design educators believe that the graphic design education system is declining in Jordan (Haddad, 2007; Alkholy, 2010; Al-Qur'an, 2012). One important reason is the admission system. Most of Arts and design faculties in Jordanian universities accept large numbers of untalented students in their design schools every semester. Most Public universities required the minimum grade of $65 \%$ in the Certificate of Secondary Education, and $60 \%$ is required by private universities. There is no admission evaluation exam, except for a couple of public universities, which held a sham admission evaluation exam (Al-Qur'an, 2012). Graphic design schools in Jordan concentrate on graduating operators, with good software skills, but not talented thinkers and problem solvers. Graphic design educators believe that there is a need to improve the admission system to graphic design programs in Jordan to distinguish talented and gifted students only for enrolment (Alkholy, 2010; Al-Qur'an, 2012).

There is a consensus amongst design practitioners and design educators regarding the decline in the quality of graphic design graduates from Jordanian universities. Jordanian graphic design practitioners believe that one of the most important causes of this decline is the lack of talented students in graphic design programs. The designers agree with the educators that the majority of the fresh graduates who join the market have skills in computer design programs but with no talents (Alkholy, 2010; Al-Qur'an, 2017).

Both educators and practitioners believe that graphic design graduates, from Jordanian universities, have sufficient technical skills but with no proper talents. They consider talent a key element in improving the quality of design graduates. This study aims to examine the role of talent and skill, to answer the question of which has the most prominent role in producing visual communication materials talent or skill?

To answer that, the researcher conducted and supervised several experiments on design students and fresh graduates. The students were exposed to different assignments in which some of these assignments were to produce designs for actual clients, budgets, and deadlines. The assignments included designing and producing a 
multipage publication, short movie, and poster design. All participants in this study were unfamiliar with the proper techniques and programs, besides the equipment needed to produce their assignments. They were asked to attend briefings and follow-up meetings with the clients. They have been treated as full-time employees; they worked eight hours a day and were given tight deadlines to deliver.

\section{Study hypothesis}

In this study, a skilled student is defined as a student who has the needed knowledge to use appropriate computer design programs or appropriate artistic techniques to deploy them to solve design problems. A talented student is a gifted student who has above average abilities, commitment, and creativity to solve a design problem and develop skills.

This paper argues that talented design students and practitioners are capable of solving various kinds of design problems, even without having the needed skills. They could learn and develop new skills through hard work and compressure.

\section{Study question}

This paper examines the role of talent and skill, to answer the question of which has the most prominent role in producing visual communication materials talent or skill?

\section{Literature review}

To answer the study question, definitions of the terms talent and skill need to be explained. After Reviewing and analysing literature, it was found that there is no agreement among the researchers on a single definition for the term talent (Mensah 2015). In language, Merriam-Webster (2019) defines talent as "(a) a special often athletic, creative, or artistic aptitude, and (b) general intelligence or mental power, and (c) the natural endowments of a person". Mazurkiewicz (2018) assumes that a talented person is a person who has a high degree of aptitude with above-average abilities or skills. Mensah (2015) considers it as the personal abilities and the experiences that the individual uses to reach more distinguished achievements. Piirto (2009) describes talent as the person's products that result from his different activities. Joseph Renzulli, who is widely cited by researchers who write about talent and gifted people (Jones et al, 2019), defines talent as interaction between three basic groups of human attributes (Renzulli, 2011, p.87). He labels the groups as "Above-average general abilities, high level of task commitment, and high level of creativity" (p. 87). He explains that talented individuals are those who have got these clusters or have the ability to develop them to interact with different situations (Renzulli, 2011).

In general, talent concerns features that are much more sustaining and individual in its nature than the skills and knowledge that could any individual obtained by various means. Hence, talent is an inborn characteristic that can't be learned or taught (Buckingham and Vosburgh, 2009, Davies and Davies, 2010).

Skill in the language is defined by Merriam-Webster (2019) as "(a) the ability to use one's knowledge effectively and readily in execution or performance" and "(b) a learned power of doing something competently: a developed aptitude or ability". Tonnessen (2011) believes that skills are mixtures of "automaticity and awareness". He explains that it is about "conscious monitoring and possible correction in the performance of the task" (Tonnessen, 2011, p.154). Green (2011) defines skills as a personal quality with three key features: productive, expandable, and social (P.5). In general, skills are the sum of what an individual learns in his life by practicing different sorts of human activities, it is changeable and developable.

Based on that, a skilled student will be defined, in this study, as a student who has the needed knowledge to use appropriate computer design programs or appropriate artistic techniques to deploy them to solve design 
problems. A talented student will be defined, in this study, as a gifted student who has above average abilities, commitment, and creativity to solve a design problem and develop skills.

\section{Study methodology and procedures}

In this qualitative empirical study, the researcher conducted and supervised some experiments on design students and fresh graduates across two years. The students were exposed to different assignments, similar in their nature, in terms of scale and requirements, to the assignments given to practitioners in design firms. Some of these assignments were to create designs for real clients, budgets, and deadlines. The tasks include producing a multipage publication, short movie, and poster design.

All participants in this study were unfamiliar with the proper techniques and programs, besides the equipment needed to produce their assignments. They were asked to attend briefings and follow-up meetings with the clients or the researcher. The researcher exposed them to the employee's experience such as full time working hours and tight deadlines to deliver.

The first experiment intends to evaluate the ability of an unspecialized talented student gaining skills, in a tight deadline, to compete with other specialized students who are skilled in particular software.

The outcome of the first experiment led to organizing a second one. In the second experiment, the aim was to assess the ability of a student to obtain the required software skills and to deliver the required design under pressure. For that, a talented beginner student positioned in a professional atmosphere and observed while managing a project for a real client. Based on the results of the second experiment, a third experiment was needed to compare the creative outcome of a pair of teams handling the same project. Team of professionals, who are considered experts in the field of the project and rated skilled in this field, yet, without any former design education, with a different team of fresh graduate talented designers without any previous experience either skill in the field of the offered project.

\section{Poster advertising experiment}

This experiment aims to assess the ability of an unspecialized talented student gaining skills, in a tight deadline and usual atmosphere, to compete with other specialized students skilled in particular software.

The researcher selected Graphic Design 3 (GD3) class for his first study. GD3 is a specialized course in advertising and poster design for graphic design students, which is a major requirement in the third year of their study. Prerequisite courses must be completed successfully to enroll in this course, which are Graphic Design 2 (publication design), Graphic Design 1 (branding and corporate identity), Basics of Graphic Design and Colour Methods and Applications. In these courses, students learn free-hand drawing techniques, Photoshop, Illustrator, and InDesign computer programs.

The chosen class for this study consists of 7 graphic design students who completed prerequisite courses plus one candidate student who has been selected to join the course for 3 weeks. This candidate was chosen based on close observation by the researcher to several students for a full semester. The candidate's major was Interior Design. She was in the third year of her study. She finished one single prerequisite, which is Colour Methods and Applications. She has no skills to operate neither Photoshop nor Illustrator, the needed programs to build up poster designs.

The visiting student was given two weeks to learn by herself to use Illustrator and Photoshop programs. During the observation and searching period, this candidate showed, comparing to her colleagues, above-average 
abilities, commitment, and creativity to solve a design problem and develop skills. However, she did not have the needed knowledge to use particular computer design programs or particular artistic techniques to deploy them to solve design problems. Comparing to other students in this class, this candidate is considered a talented but un-skilled student.

One exercise that has been given to the class is to learn to place a sign concerning the working area borders. After explaining the lesson through a lecture punctuated by the presentation of some examples of related work, the class has been given an assignment to create posters that guides the eye of the recipient by using various elements, with focusing on using images that convey a sense that it reaches beyond the working area, as the following brief:

- The topic is the ZOO. Any kind of zoos is accepted. Existed or invented.

- Each student must focus on a specific target audience of his choice (kids, teenagers, adults, families, birds lovers, mammal lovers, etc.) with a clear message.

- Series of 5 posters are required (4 posters showing the 4 different ways the eye enters the working area: one-sided, crossed, encircled, and filled +1 poster concentrating on using typography)

- The posters must contain 5 different massages with different headlines and body copy.

- Students are required to maintain unity and consistency in the series.

- The student could use either Arabic or English language

- The size is A3/150 DPI resolution and 5mm bleed

- 1 week to complete the task

\section{The Results}

To analyze the result of this exercise; the work of two students has been chosen randomly with the visiting student's work. The work of the three students has been reviewed and matched with the brief. The results could be summarized as the following:

\section{The work of the first student}

The work of the first student (Figure 1) did not target a specific audience. The target remained generic, which was opposite the brief requirements. Although the work did succeed visually in maintaining the ways the eye enters the working area and the typographical poster. The focus was on one message only stating: "Don't let this be my last Selfie", which was repeated, as a fixed form, throughout the five posters. No decent body copy has been employed to support the headline. Besides, four of the posters' hold text alignment problems. The logo implementation was unaccepted because there is no suitable white space around the icon and the name. There was no proper consistency and unity because of using the same headline. There was a color differentiation issue between the posters. Additionally, the artworks failed to meet the technical specifications required by the brief. 


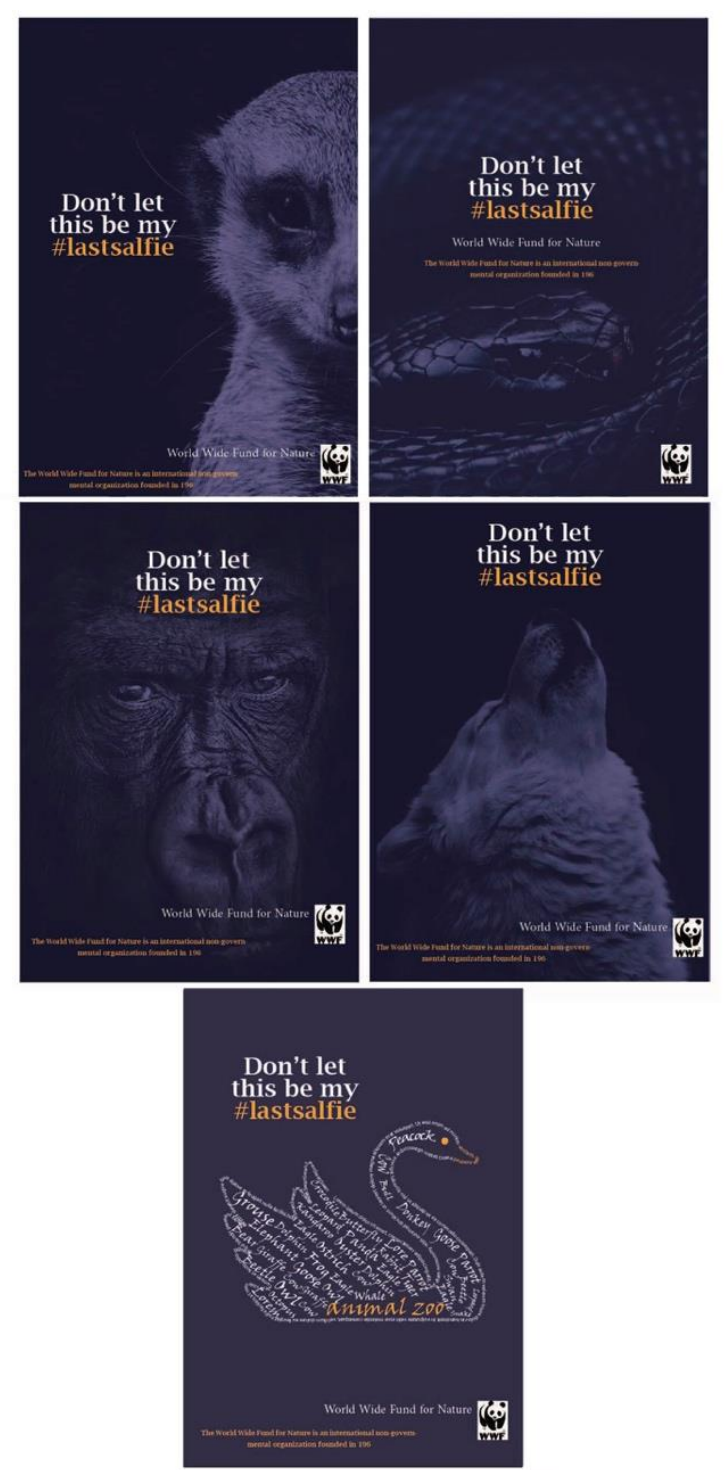

Figure 1The work of the first student for the ZOO project.

\section{The work of the second student}

Similar to the work of the first student, the work of the second student (Figure 2) did not target a specific audience. The target in the posters remained generic, which is not matching the brief requirements. However, it seems that the work of the second student has visually pass in maintaining the ways the eye enters the working area. Likewise, and to some extends, in the fifth poster. Another issue is that the second student did employ animal species names as headlines, which has no clear message. In return, some "Lorem Ipsum" text has been used rather than supporting the headline with a proper body copy that holds meaning. Furthermore, this work lacks consistency and unity between the four posters and the typographical one. Another similarity with the first student is the failure to meet the technical specifications required by the brief. 


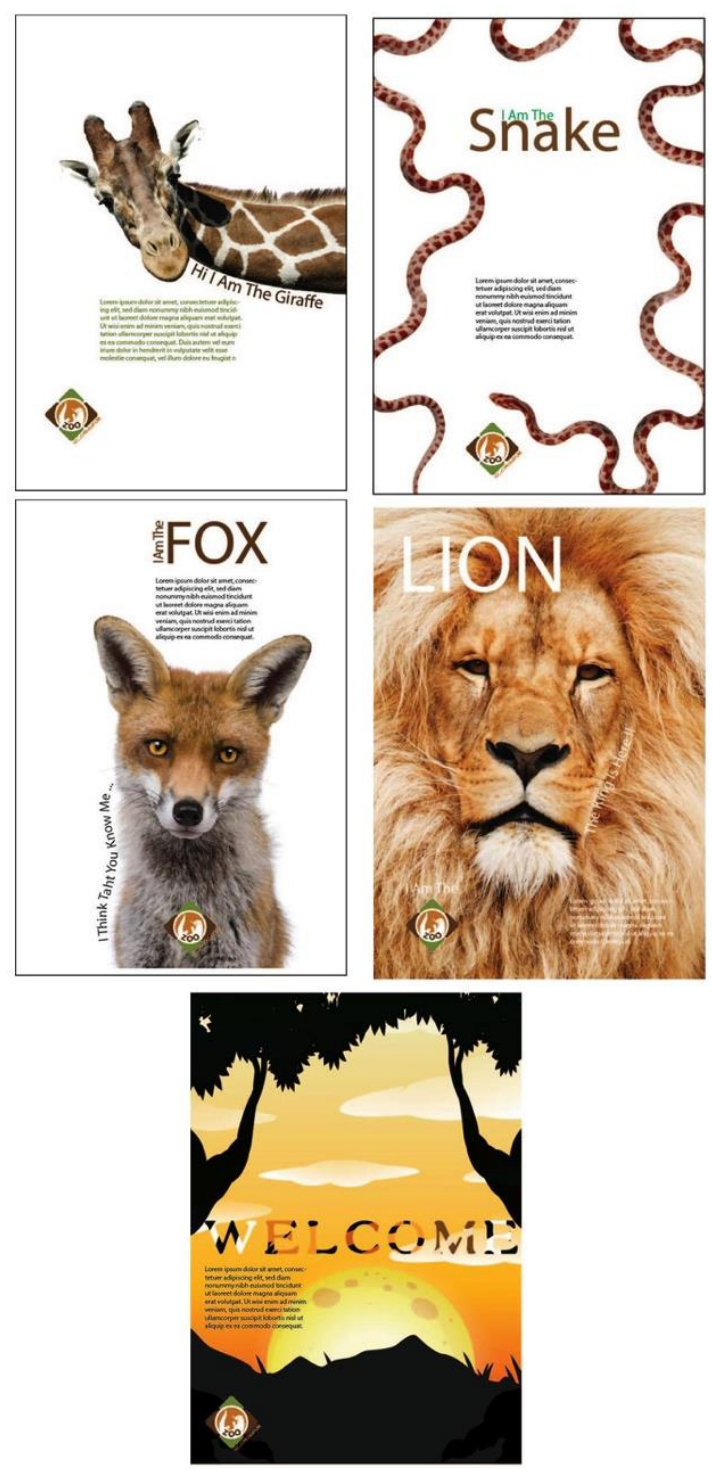

Figure 2 The work of the second student for the ZOO project

\section{The work of the visiting student}

Linking to the first two students, who failed to match the brief requirement regarding the target audiences, the visiting student has succeeded at this point (Figure 3). The concept was to target a specific audience of the aquarium fish lovers. The messages used are considered adequate for such informative posters. Similar to the first two students, the visiting student's posters did work in maintaining the ways the eye enters the working area. Further, she presented an accepted typographical sign. Comparing to the first two students, who both neglected this issue, the work of the visiting student focuses on designing informative messages. Each poster has a different headline and body copy that implements separate information. These messages provide the target audience with unique soft information about marine life to attract them visiting the zoo. Besides, the logo implementation was accepted. The visiting student successfully established consistency and unity in her work by employing font type, sizes, and decent color management.

Unlike the work of the first two students, the work of the visiting student shows accepted relationships between the body copy, the image, and the headline. Besides, the work met the technical specifications required by the brief. 

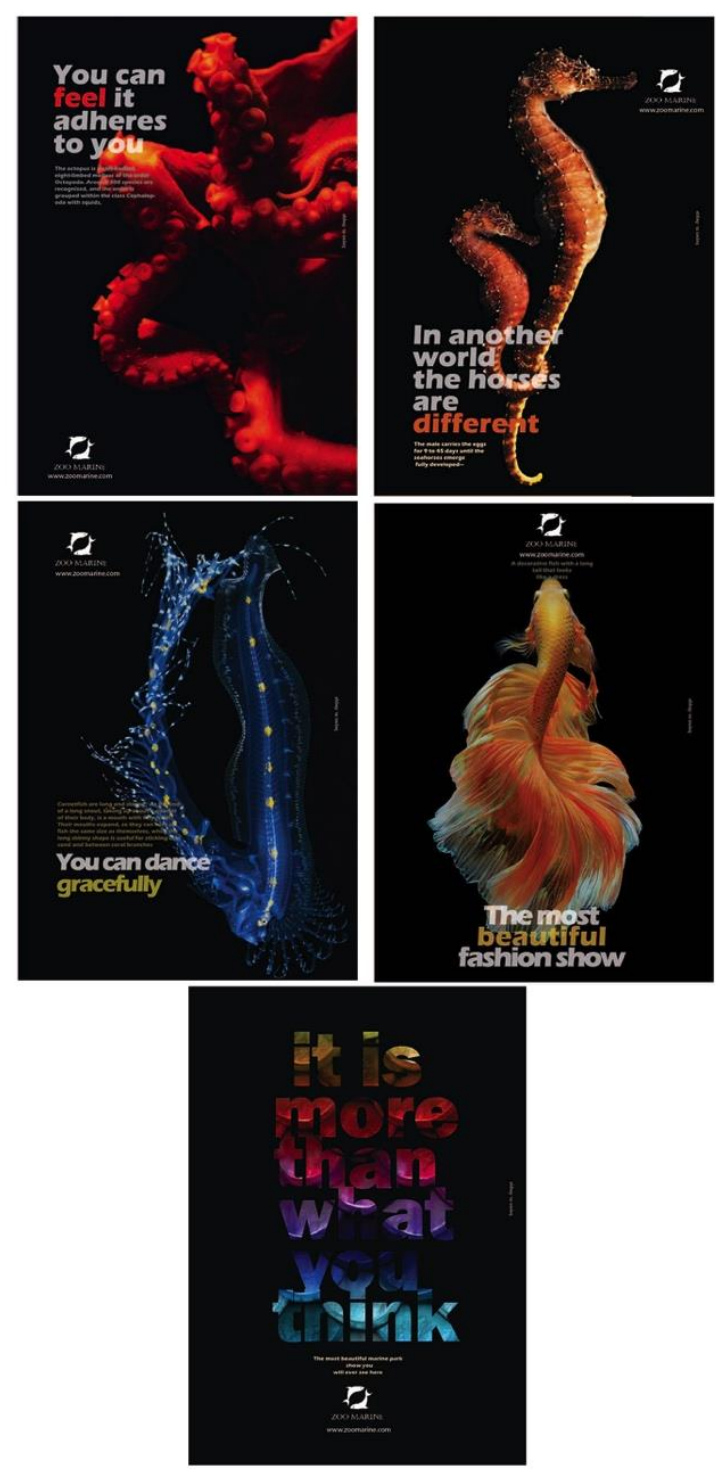

Figure 3 The work for the visiting student for the ZOO project

\section{Findings of the experiment}

It is clear from the resulted posters that the visiting student's work has stood out from others. One reason could be the way she creatively handled the brief conversely than most of the other specialized students did. It is also explicit that the creative abilities of the visiting student are more distinct than the average abilities. Although she has no Photoshop or Illustrator skills, the visiting student shows dedication and energy to teach her-self these programs in two weeks to create advertising posters.

It is worth to mention that the visiting student's posters were selected to be exhibited at the annual student exhibition, which has been held in June 2019 at the faculty of arts and design in Zarqa University.

This experiment shows that the skills some students have in graphic design software are not the only tool in solving design problems or in providing creative solutions. On the other hand, it shows that talented design students could train themselves to build and develop the needed software skills to solve a design problem and provide creative solutions. However, in this experiment, the visiting student put in a semi-routine atmosphere that she used to it. She remained at the same university, the same faculty, and with the same people. In short, 
this experiment occurred in semi-normal conditions. Hence, there is a need to assess the ability and the commitment of a talented student to obtain the needed software skills and to perform under different pressure and new atmosphere; in a professional place, with professional people, and for real clients.

\section{Publication experiment}

This experiment aims to assess the ability of a talented beginner student to gain the required software skills and to perform under different pressure and new atmosphere.

Graphic design students, usually, take Graphic Design 2 course (GD2) in the first term of their third year. This course is designed to familiarize the student with page layout principles, publications, and software used in visual communication design, concentrating on InDesign. Based on the researcher's experience, in teaching GD2, students usually require a full term (14 weeks $=28$ session $=70$ hours + around 30 hours of homework and self practicing) to learn the basics features of the InDesign program (main menus and fundamental tools) to be able to employ it in designing a multipage publication. To evaluate the students' perception and their implementation abilities, students are usually required to produce a multipage publication on the final exam. Based on the results from the exams, the researcher noticed that most of the students do not give enough attention to the details and to maintaining the following issues:

- Typographical principles, including kinds, sizes, and colors.

- Paragraphing principles, including alignments, leading and kerning.

- Page layout principles features, including column size, margins, and gutters.

- Printing technical details, including bleed and binding.

For this experiment, one student has been selected based on close observation by the researcher to several students for a period of full term. This student has finished the first year in the graphic design program and started with the second year. Within the observation period, this student showed, comparing to her colleagues, above-average abilities, commitment to finish tasks, creativity in solving design problems, and abilities to develop new skills. Although, this student held basic skills in operating software, such as Photoshop and Illustrator. However, she holds no skills in operating InDesign software, the required program for publication design. In short, she had no previous training or the needed knowledge or the fundamentals of creating publications. Comparing to other candidates observed by the researcher, this candidate considered a talented designer but an un-skilled candidate in publication design.

\section{Task}

The selected student was invited to be a trainee at the researcher's practice during the summer holiday. For three months, she has been under the close supervision of the researcher, treated as a full-time employee in terms of working hours. The first assignment was to entirely handle a mega-project annual progress report for an overseas construction company. This publication consists of 120 pages that including designing, layouts, and photo editing. There were more than 100 tables and 200 images with maps and construction plans.

As a part of her job, the student had to join briefing sessions and follow-up meetings with the client. She spent her first two weeks between meetings and communication with the client, collecting materials, training Photoshop, and mostly teaching herself InDesign. She relied on online tutoring plus consulting the researcher when needed. 
Two options for two concepts have been created by the researcher and presented to the client. After two weeks of the first briefing, the client decided on one option. During this period, the candidate shows an exceptional level of improvement on InDesign self-training. Therefore, she started the implementation process.

Two weeks after the first briefing, the client decided on one option of two that have been created by the researcher. During that time, there was an exceptional level of improvement shown by the intern in InDesign training. Subsequently, she started the implementation process of the publication under the close supervision of the researcher. Her duties require designing, layouts, and photo editing. The entire process accomplished in 7 weeks. However, due to the nature of the project, there was an on-going development on the construction site. These developments led the client to request more amendments to the content aiming to reflect the progress in the construction site. These amendments caused 8 weeks of delay in production.

\section{Results of the second experiment}

During the first 7 weeks, the intern showed significant progress in mastering the InDesign program. She spent around two weeks of self-training, which equals 80 working hours. This time considered less than the average time the student usually spends to master InDesign in GD2. Comparing to the other students, in the GD2 final exam, this intern showed a high level of abilities, creativity, and commitment to this project. She handled typographical principles, paragraphing, layout, printing and other technical details with a high level of responsibility. The researcher observed no errors or miner problems during the entire implementation process, with one exception related to communication with the client. The intern was not comfortable dealing directly with the client, which could be considered, based on the researcher's experience, a common reaction of many junior designers.

This experiment shows that a talented beginner student could perform adequately in gaining new technical skills under significant pressure of working for a real client, existing project, actual deadline, and a real budget. These skills may include learning new graphic design computer programs or new design principles or techniques.

\section{Movie production experiment:}

This experiment aims to compare the creative outcome of two teams handling the same project. Team of professionals, who are considered experts in the field of the project and recognized skilled in this field, still, without any former design education, among a separate team of fresh graduate talented designers without any previous experience or skill in the field of the offered project.

The researcher's studio has been approached to produce a 15 minutes special documentary. This documentary aims to tell the story of a 60 years old popular traditional restaurant in Jordan.

The art direction was to utilize the sand drawing technique in creating this movie. Sand drawing is known as a performing art, where the artist uses fine sand to create a sequence of illustrations that tells a story. Sand pictures are drawing frame by frame on a lighted flat surface (lightbox) with music played in the background. The drawing process of the frames recorded by a video camera and edited to form an animated movie. Being the creative director in the studio, the researcher created the concept, wrote the narrative script as part of the voice over, and transcribed the music description. Following the client's approval on the storyboard, the task was assigned for two production teams to produce the movie, one based overseas and the second is in-house. Both teams were not informed about the existence of each other. The music has been assigned to an independent composer to produce. 
The first team consisted of a10 years experience sand artist, cameraman, and a video editor. None of the first team's members have any former design education. Upon their proposal, this team was given 4 weeks to deliver the movie. The other in-house team, which was hired specially for this mission, was consisted of two freshly graduate designers. One talented graphic designer, skillful in video editing, the other is a talented interior designer, who has high skills in free-hand drawing. None of the team members gained any experience in sand animation movies. Both of them were former students of the researcher. Based on the researcher's experience in teaching them, they may be considered being talented designers in drawing and film editing, yet un-skilled in the sand animation procedure.

\section{Results of the third experiment}

\section{The first team}

The production process remained supervised and art-directed by the researcher. The researcher employed video conference calls, phone calls, and video chat over MSN plus WhatsApp. The team has given a margin of discretion, to adjust some dramatic details, to avoid inconsistency with the drawing method.

Along with the approved storyboard plus the voice-over, the researcher equipped the team with all needed components to develop the scenes. The material involved copies of clear historical photographs for the founder of this restaurant (Hashim), the founder's father (Saber), the former shop, the old city, and photos of multinational figures visiting the restaurant. There were several issues raised while supervising the work of the first team, which could be shortened in the following points:

- The first scene (Figure 4) requires a drawing of the movie's logo that consists of calligraphy in the Arabic language. The team missed to match it with the initial due to technical issues.
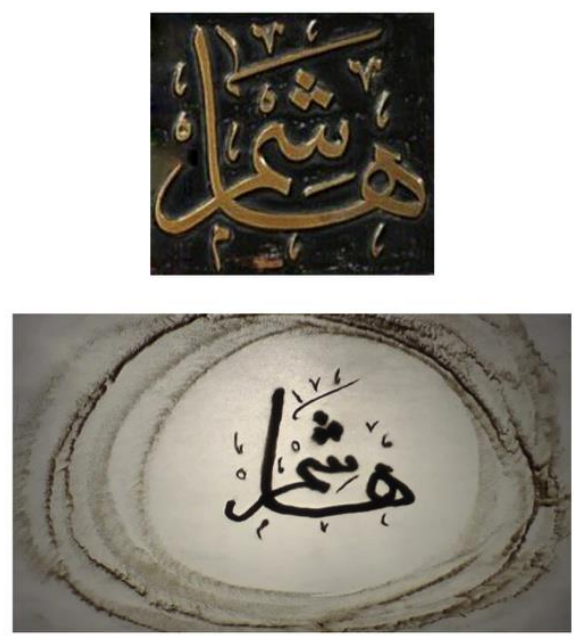

Figure 4 the first scene. At top is the original; bottom is the first team's emulation.

- A scene required portraiture for Saber (Figure 5). The team failed to match it with the original and arranged to do a major, yet, unaccepted modification to the picture. 


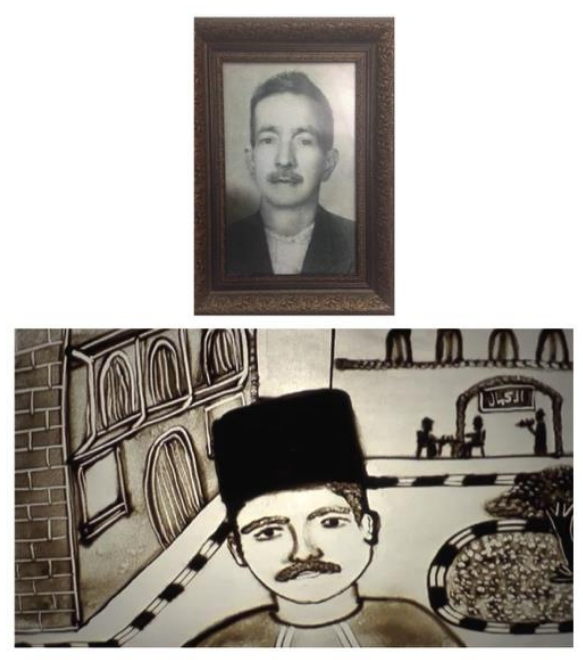

Figure 5 Sabir's scene. At top is the original; bottom is the first team's emulation.

- An unacceptable striped shadow remained seen throughout the scenes following the artist's arms (Figure 6). The team insisted that this is an unsolvable technical obstacle.

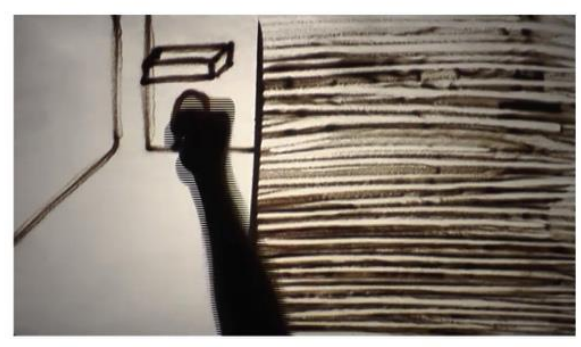

Figure 6 sample of the stripped shadow following the artist's arm in the scenes.

- One extra major scene needed portraiture for Hashim (Figure 7) with a particular request from the client to emulate the original. The outcome was not accepted. 

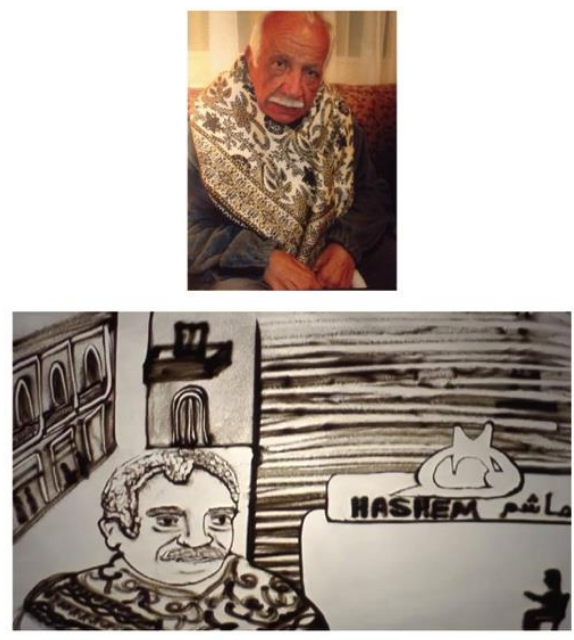

Figure 7 Hashim's scene. At top is the original; bottom is the first team's emulation.

- There was no sense of perspective in most of the scenes (Figure 8).

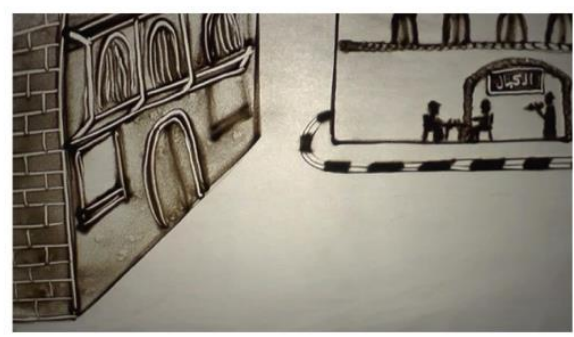

Figure 8 a scene showing the perspective drawing in most of the scenes.

- The team dropped a whole major scene contains portraits for some celebrities who visited the restaurant over the years. The team couldn't produce it adequately.

Although the first team has delivered the movie on time, the final product shows a lack of attention to the artistic and the technical details.

\section{The second team}

The mission of the second team lasted longer and was more complex than the first team's. To start building the movie, this team lacked first to master the knowledge of making such a movie. Members of the team had no experience in making this kind of film. Accordingly, and as a first move, the interior designer, who joined the team to manage the sand drawing responsibility, enrolled in an early step before the video editor. He spent two weeks, under day-to-day supervision by the researcher, exploring and examining the sand drawing method, establishing the studio, and setting up the gear required for the production. To develop and enhance this skill, he spent an extra two weeks exercising, viewing and reviewing movies for sand artists' performances. Around this stage, the video editor joined the team to work in parallel with the sand artist to position the final setup and settling the production operations. The production process that including drawing, filming, editing, and mixing, was accomplished in duration of two weeks. 
Compared to the first team, it was perceived that the second team did none of the technical or the artistic errors made by the first team. In which the second team successfully implemented the opening scene that requires a drawing of the logo, which was disappointed in the first team's movie (Figure 9). Besides, each of the portraits' scenes (Figure 10), included Hashim's scene (Figure 11), were implemented in a suitable essence. Also, the second team has succeeded in eliminating the shadow stripes from the videos, which remained an obstacle in the first team's work. Additionally, and opposite the first team's work, the second team successfully controlled the sense of perspective throughout the movie. Furthermore, the celebrities' scenes that were canceled by the first team were successfully delivered in high quality by the second team.
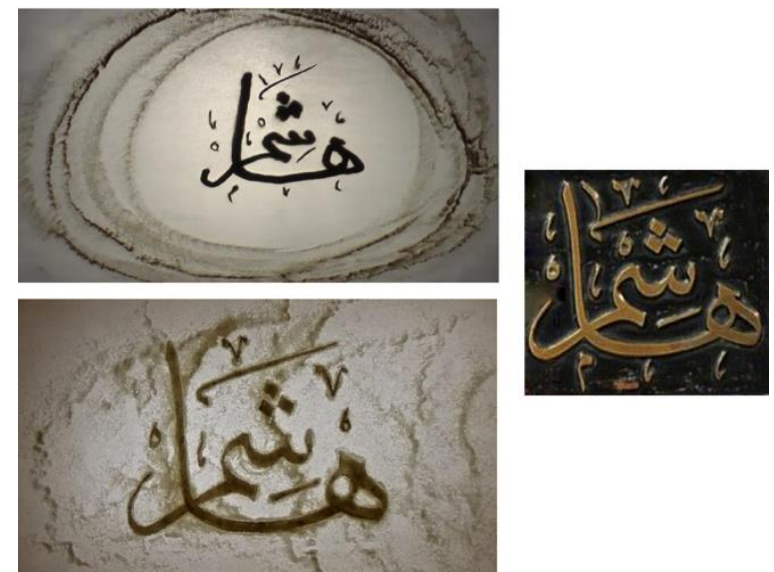

Figure 9 the opening scene. Above is the first team's work, below is the second team's work, and at the right side is the original logo.
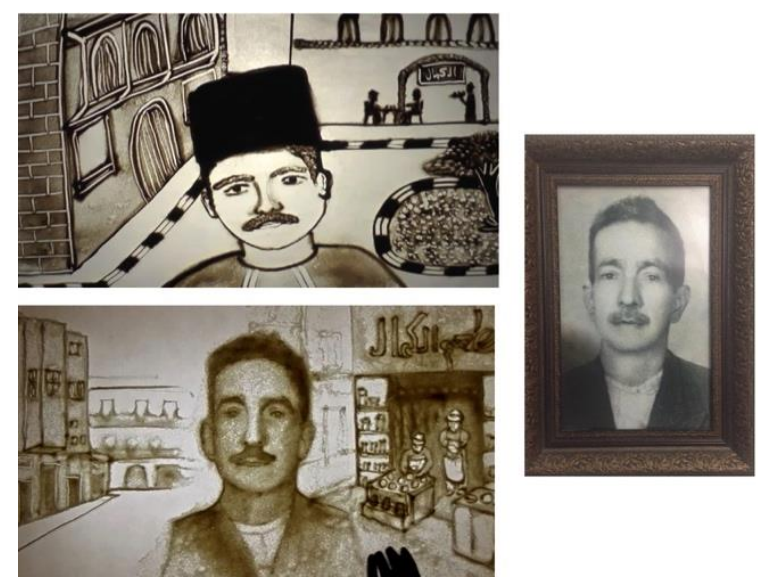

Figure 10 Sabir's scene. Above is the first team's work, below is the second team's work, and at the right side is the original picture of Sabir. 

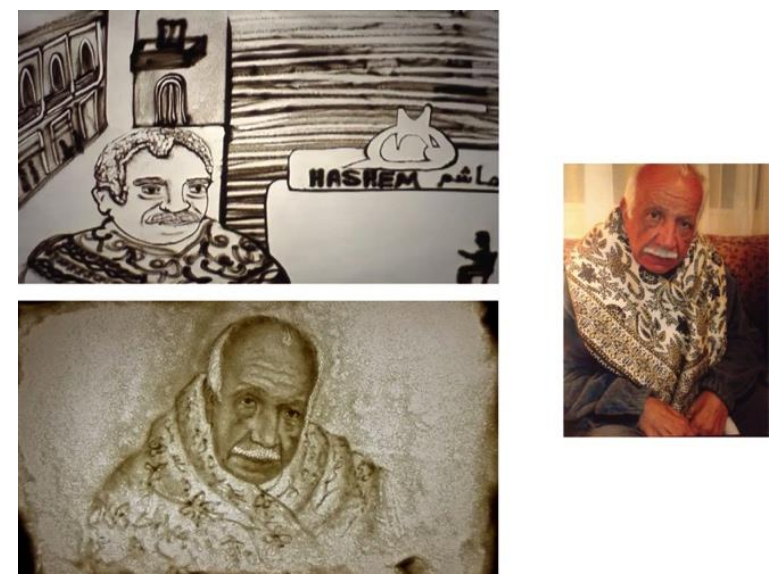

Figure 11 Hashim's scene. Above is the first team's work, below is the second team's work, and at the right side is the original picture of Hashim.

One technical issue faced by the second team was to maintain a high contrast of the scene, which has been successfully done by the first team in their movie. The second team has resolved this issue in the next animation projects.

Both movies were presented to the client to decide on one of them. The client approves the second team's movie.

\section{The results of the third experiment}

The process and the outcomes of this experiment reveal that, in any case, talent could be more relevant than skill. Talented designers could gains and develop the required skills to accomplish any given design project. Exploring methods and practicing techniques could allow gaining new skills. It further exhibited that proper design education could be more valuable than the experience in some visual communication design projects.

\section{Final results and conclusions}

This paper examines the role of talent and skill, with the purpose to answer the question of which has the most prominent role in producing visual communication materials talent or skill?

This study found that a talented designer, whether he or she is a student or practitioner, who lacks certain skills, but are necessary to solve a design problem, could solve this problem if he or she seeks to acquire the required skills. Talented designers could self-train themselves to build and develop any needed skills to solve a design problem.

The study found that talent, skill, and design education are essential concerning practicing visual communication design. It also revealed that talent ranks before skill.

\section{Acknowledgements}

This research is funded by the Deanship of Research in Zarqa University /Jordan 


\section{References}

Alkholy, I., 2010, 'Assume your service is bad: Teaching graphic design in Jordan', International Journal of Arts and Science: Multidisciplinary Conference in Rome, 22-25/10/2010. Received from author by email in 21/10/2010.

Al-Qur'an, H. A. D., 2012, 'Comparative study of graphic design education in Jordanian universities: towards best practice'. PhD thesis, University of Wollongong, NSW, Australia, 1 october 2012.

Al-Qur'an, H. A. D., 2017, 'Identification of the Significant Competencies in Graphic Design in Jordan: the Market Requirements', Dirasat, 44(1), 117-125.

Buckingham, M., Vosburgh, R., 2009, 'Function: It's the Talent, Stupid! Identifying and developing talent, one person at a time, becomes our defaming challenge', Human Resource Planning, 36(3), 19-26.

Davies, B., Davies, B. J., 2010, 'Talent management in academies', International Journal of Educational management, 24(5), 418-426.

Green, F., 2011, 'What is Skill? An Inter-Disciplinary Synthesis', LLAKES Research Papers, pp. 1-25.

Haddad, Z., 2007, 'Design Education in Jordan: Facing the Change', Abhath Al-Yarmouk, 23(3), 905-918.

Jones, B. L., Perez, K., Hogenstijn, M., 2019, 'Development of Talented University Students - an Intercontinental Perspective', ResearchGate, 20 june 2019, Date of access 2/6/2019.

Mazurkiewicz, A., 2018, 'Career Shaping of a Talented Employee', In: Business and Non-profit Organizations Facing Increased Competitions and Growing Customers' Demands, edited by A. Nalepka, A. Ujwary-Gil, 1st edn, National Louis University, Warsaw.

Mensah, J. K., 2015, 'A “coalesced framework” of talent management and employee performance for further research and practice', IJPPM, 64(4), 544-566.

Merriam-Webstar (online dictionary), Date of access: 5/5/2019. https://www.merriamwebster.com/dictionary/talent

Piirto, J., 2009. Entry. Creativity assessment. In B. Kerr (Ed.), Encyclopedia of giftedness, creativity, and talent, Los Angeles, CA: Sage Publications, pp.206-209.

Renzulli, J. S., 2011, 'What Makes Giftedness? Reexamining a Definition', Kappan, 92(8), 81-88, The article was originally published as "What Makes Giftedness? Reexamining a Definition, Phi Delta Kappan, 60(3) (November 1978): 180-184, 261.

Tonnessen, F. E., 2011, 'what are skills? Some fundamental reflections', L1-Educational Studies in Language and Literature, vol 11, 149-158. 